\title{
DETERMINAÇÃO DA QUALIDADE HIGIÊNICO-SANITÁRIA DE ALIMENTOS SERVIDOS EM RESTAURANTES SELF- SERVICE
}

SOARES, L. A. ${ }^{*}$; SOUZA, R. O.1; CRUZ, L. F.1; COELHO, M. B. ${ }^{1}$; GOMES, A. A.2; SOARES, J. O.2; OLIVEIRA, L. F.3; MAGALHÃES, J. T. ${ }^{3}$

1 Alunos de graduação da Universidade Federal de São João Del Rei 2 Profissionais da diretoria de Vigilância em Saúde - Secretaria Municipal em Saúde/Divinópolis/MG 3 Professores da Universidade Federal de São João Del Rei

*e-mail: leticia-soares06@hotmail.com

\section{Resumo}

Nos últimos anos a procura por restaurantes self-service aumentou significativamente em virtude da diminuição do tempo disponível da população. Relatos na literatura mostram que os alimentos ingeridos em estabelecimentos comerciais nem sempre apresentam condições de preparo adequadas. Desta forma, para se evitar a contaminação por microrganismos patogênicos, algumas condutas durante a manipulação do alimento são essenciais para garantir sua segurança, como é o caso das Boas Práticas de Fabricação (BPF). O grupo dos coliformes fecais, pertencentes à família Enterobacteriaceae, são usados para indicar as condições higiênico-sanitárias inadequadas durante a manipulação ou armazenamento do alimento, informando assim possível contaminação por patógenos. Neste sentido, o presente trabalho teve como objetivo analisar a presença de coliformes fecais em alimentos comercializados em restaurantes tipo self-service do centro da cidade de Divinópolis - MG. Foram coletados 87 alimentos, os quais foram divididos de acordo com seu método de preparação em três grupos: A (saladas cruas), B (alimentos cozidos) e C (alimentos mistos). As análises foram realizadas através do número mais provável (NMP) e foram interpretadas de acordo com a resolução 12 de 2001 da ANVISA. Sendo assim, o grupo A apresentou 10,52\% de não conformidade, o grupo B $6 \%$, enquanto o grupo C 38,88\%. Esses resultados sugerem que a presença de coliformes fecais em alimentos crus está relacionada ao fato deste alimento não ter sido submetido ao tratamento térmico, já que estes microrganismos são termossensíveis. A 
contaminação nos alimentos com multi-ingrediente pode ser devido a grande manipulação durante o preparo, e, possivelmente contaminação cruzada. Os resultados evidenciaram a precariedade quanto a cuidados sanitários, tornando necessária a intervenção no processo de produção, manipulação e conservação do alimento, com emprego adequado das BPFs.

Palavras-chave: coliformes, alimento, self-service

Apoio financeiro: FAPEMIG, CNPq e UFSJ 